\title{
Evaluation of changes in liver function test in first, second and third trimester of normal pregnancy
}

\author{
Mukesh G. Gohel $^{1 *}$, Anant G. Joshi ${ }^{1}$, Jitendra S. Anand ${ }^{1}$, Jemil S. Makadia ${ }^{1}$ \\ Chandrakant P. Kamariya ${ }^{2}$
}

\begin{abstract}
${ }^{1}$ Department of Biochemistry, B. J. Medical College and Civil Hospital, Asarwa, Ahmedabad-380016, Gujarat, India
${ }^{2}$ Department of Biochemistry, P.D.U. Medical College, Rajkot, Gujarat, India
\end{abstract}

Received: 17 October 2013

Accepted: 27 October 2013

\section{*Correspondence:}

Dr. Mukesh G. Gohel,

E-mail: mks.gohel@gmail.com

(C) 2013 Gohel MG et al. This is an open-access article distributed under the terms of the Creative Commons Attribution Non-Commercial License, which permits unrestricted non-commercial use, distribution, and reproduction in any medium, provided the original work is properly cited.

\begin{abstract}
Background: Understanding of physiological adaptations of normal pregnancy remains a major goal of obstetrics, and without such knowledge, it is almost impossible to understand disease processes that can threaten women during pregnancy. Aim of this study is to evaluate changes in serum liver function tests in normal pregnant women in first, second and third trimester.

Methods: A hospital based cross sectional in vitro study conducted at Civil Hospital, Ahmedabad (India). A study consists of 150 pregnant women and 50 matched control. Among the 150 pregnant women, 50 were in first trimester, 50 were in second trimester and 50 were in third trimester. Serum sample was taken and assessed for routine liver function tests.

Results: Serum total and direct bilirubin concentrations were significantly lower in second and third trimester. Serum ALT and AST activity was slightly but significantly increased in third trimester. Serum ALP activity was significantly higher in second and third trimester. ALP activity increases as pregnancy advances. Serum GGT values were significantly lowers in third trimester. No significant change in serum total proteins concentration, but serum albumin concentration was significantly lower and serum globulin concentration was significantly higher in all three trimester. Serum albumin/globulin ratio was significantly reduced in second and third trimester.

Conclusion: Such changes in in liver function tests during normal pregnancy can be misinterpreted as pathological and can also unmask or worsen preexisting disease. So the identification and understanding of these physiological changes in pregnancy is important for the diagnosis of liver diseases during pregnancy.
\end{abstract}

Keywords: Liver function tests, Pregnancy, Liver diseases

\section{INTRODUCTION}

The anatomical, physiological and biochemical adaptations to pregnancy are profound compared to nonpregnant women. Many of these remarkable changes begin soon after fertilization and continue throughout gestation. Such changes occur in response to physiological stimuli provided by the fetus and hormonal changes that accompanies pregnancy in mother. During normal pregnancy, virtually every organ and system under goes anatomical and functional changes that can alter appreciably the criteria for diagnosis and treatment of diseases. So sometimes these physiological adaptations could be perceived as abnormal. Thus physiological adaptations of normal pregnancy can be misinterpreted as pathological and also unmask or worsen preexisting disease. The understanding of these adaptations to pregnancy remains a major goal of obstetrics, and without such knowledge, it is almost impossible to understand the disease processes that can threaten women during pregnancy. ${ }^{1}$

The pregnant woman experiences physiological changes to support fetal growth and development. During 
pregnancy, the serum estrogen and progesterone levels increase progressively and reach a maximum during the third trimester. These sex steroids have effects on metabolic, synthetic, and excretory hepatic functions. ${ }^{2}$ The increase in plasma volume that occurs during pregnancy leads to haemodilution and decreases the serum protein concentrations. Serum alkaline phosphatase levels increase in late pregnancy because of both a production of the placental isoenzyme and an increase in the bone isoenzymes. ${ }^{3}$ It is therefore not surprising that changes in liver function tests (LFTs) occur during pregnancy. Nevertheless, except for increased alkaline phosphatase levels, which have been clearly demonstrated, the changes in the other LFT values have not been clearly established, and a recent review in this field has shown that there is some discordance in the literature. The identification of these physiological changes is important for the diagnosis of liver diseases during pregnancy.

The physiological changes in liver function in pregnancy are commonly transient and remain only during pregnancy periods only, then it corrects spontaneously. But disorders arising in pregnancy, such as pre-eclampsia and eclampsia, acute fatty liver of pregnancy (AFLP), haemolysis, elevated liver enzyme and low platelets (HELLP) syndrome, cholestasis, hyperemesis gravidarum and isolated cases of raised liver enzymes can have serious implications. Proper interpretation of liver function tests (LFTs) can lead to proper diagnosis and timely management of diseases and may reduce complications in both mother and fetus. A number of pitfalls will be encountered during interpretation of basic serum LFTs. In a prospective analysis of Bilirubin, ALT, AST and GGT in 430 pregnant women it was found that these tests were found $20 \%$ lower values in pregnant women compared to normal reference range. ${ }^{4}$

Thus, the aim of this study was to evaluate the changes in serum levels of routine liver function tests, i.e., Total and Direct bilirubin, Alanine transaminase (ALT, E.C.2.6.1.2), Aspartate transaminase (AST, E.C.2.6.1.1), Alkaline phosphatase (ALP, E.C.3.1.3.1), Gamma glutamyl transpeptidase (GGT, E.C.2.3.2.2), Serum total serum proteins, Albumin, Globulins and Albumin/Globulin ratio (A/G ratio)during normal pregnancy in first, second and third trimester pregnant women compared with a control group of nonpregnant women.

\section{METHODS}

\section{Study Design and Subjects}

This study was a hospital based cross sectional in vitro study conducted at Civil Hospital, Ahmedabad (India) over a period of one year (between March 2012 to April 2013). A cross sectional study consists of 150 pregnant women and 50 matched control (age matched nonpregnant women not receiving oral contraceptives).
Among the 150 pregnant women, 50 were in first trimester (within 1-3 month), 50 were in second trimester (within 4-6 month) and 50 were in third trimester (within 7-9 month). Subjects were recruited according to simple random sampling method meeting the selection criteria. Mean age of women in first trimester was $25.8 \pm 4.8$ years, in second trimester was $27.1 \pm 5.6$ years, in third trimester was $26.6 \pm 5.5$ years and in nonpregnant control was $26.2 \pm 3.4$ years.

Subjects not included in study if they had any of following: gestational diabetes or pregestational diabetes, hypertension (blood pressure more than 140/90mm Hg at recruitment), past history of jaundice or pruritus, chronic alcoholism, seropositivity for hepatitis B or VDRL, history of ingestion of hepatotoxic drugs (antituberculosis drugs or anticonvulsants).

\section{Ethical Considerations}

The objectives of study were explained to all eligible subjects and informed written consent of all subjects included in the study was obtained for involvement in study groups and for venepuncture. Emphasis was given that participation in this study was voluntary. The Institution's ethical committee was informed and approval taken prior to beginning of study.

\section{Questionnaire and Bio data Collection}

A questionnaire was specifically designed to obtain information which helps to select individuals according to the selection criteria of the study. The questions also focused on socio demographic data (age, sex, parity), duration of pregnancy.

\section{Blood Sample Collection}

A $3 \mathrm{ml}$ of venous blood was drawn from each volunteer using a disposable vacutainer system in Plain and Fluoride vacutainer. Serum or plasma separated within half an hour and stored at $2-8^{\circ} \mathrm{C}$ temperature till analysis was done.

\section{Analysis of Sample}

Serum total and direct bilirubin was estimated by modified Jendrassik and Grof's method. Serum alanine transaminase (ALT) activity was measured by modified IFCC kinetic method. Serum aspartate transaminase (AST) activity was measured by modified IFCC kinetic method. Serum alkaline phosphatase (ALP) activity was measured by pNPP Kinetic method. Serum gamma glutamyl transpeptidase (GGT) was measured by carboxy substrate kinetic method. Serum total protein concentration was estimated by biuret end point method. Serum albumin concentration was measured by BCG end point method. Serum globulin concentration was calculated by subtracting albumin concentration from total protein concentration. Albumin/globulin ratio (A/G 
ratio) was also calculated. Apart from liver function tests, other routine biochemical tests also performed. All biochemical analysis was carried out on automated clinical chemistry analyzer model XL 640 (Transasia Bio-medicals limited) using CORAL kits (Crest biosystems).

Reference limits of normal values in our laboratory for nonpregnant women are upto $1.0 \mathrm{mg} / \mathrm{dl}$ for serum total bilirubin, upto $0.2 \mathrm{mg} / \mathrm{dl}$ for serum direct bilirubin, upto $31 \mathrm{U} / \mathrm{L}$ at $37^{\circ} \mathrm{C}$ for serum ALT, upto $31 \mathrm{U} / \mathrm{L}$ at $37^{\circ} \mathrm{C}$ for serum AST, 80 to $290 \mathrm{U} / \mathrm{L}$ at $37^{\circ} \mathrm{C}$ for serum ALP, 7 to $35 \mathrm{U} / \mathrm{L}$ at $37^{\circ} \mathrm{C}$ for serum GGT, 6 to $8 \mathrm{gm} / \mathrm{dl}$ for serum total protein concentration, 3.7 to 5.3 for serum albumin concentration, 2.3 to $3.6 \mathrm{gm} / \mathrm{dl}$ for serum globulin concentration, 1.0 to 2.3 for serum albumin/globulin ratio.

\section{Statistical Analysis}

The data collected during the current study were recorded and analyzed statistically to determine the significance of different parameters by using GraphPad InStat statistical software. Results are expressed as mean \pm SD. The values between nonpregnant women and pregnant women in first, second and third trimesters were compared using ANOVA. $P$ value of $<0.05$ was considered statistically significant.

\section{RESULTS}

The results of LFT values for pregnant women in first, second and third trimester and nonpregnant women (controls) are compared in Table 1.

Table 1: Serum LFTs in nonpregnant and pregnant women (first, second and third trimester).

\begin{tabular}{|lllll|l|}
\hline \multicolumn{7}{|l}{$\begin{array}{l}\text { Cases } \\
\text { Variables }\end{array}$} & $\begin{array}{l}\text { Controls } \\
\text { Non pregnant } \\
\text { women }(\mathbf{N}=50)\end{array}$ & $\begin{array}{l}\text { Fregnant women } \\
\text { First trimester }\end{array}$ & $\begin{array}{l}\text { Second } \\
\text { trimester } \\
(\mathrm{N}=50)\end{array}$ & $\begin{array}{l}\text { Third trimester } \\
(\mathrm{N}=50)\end{array}$ & $\begin{array}{l}\text { Probability } \\
\text { (p value) }\end{array}$ \\
\hline Total Bilirubin (mg/dl) & $0.79 \pm 0.19$ & $0.63 \pm 0.36$ & $0.68 \pm 0.32$ & $0.55 \pm 0.26$ & 0.0002 \\
\hline Direct Bilirubin (mg/dl) & $0.18 \pm 0.07$ & $0.17 \pm 0.14$ & $0.13 \pm 0.09$ & $0.08 \pm 0.05$ & $<0.0001$ \\
\hline ALT (U/L) & $22.48 \pm 4.40$ & $23.54 \pm 11.92$ & $23.42 \pm 8.68$ & $34.22 \pm 23.57$ & 0.004 \\
\hline AST (U/L) & $20.00 \pm 5.54$ & $23.31 \pm 18.18$ & $23.88 \pm 14.99$ & $34.92 \pm 26.94$ & $<0.0001$ \\
\hline ALP (U/L) & $140.4 \pm 34.5$ & $152.5 \pm 49.5$ & $195.8 \pm 34.7$ & $399.1 \pm 147.4$ & $<0.0001$ \\
\hline GGT (U/L) & $26.14 \pm 4.77$ & $27.02 \pm 3.80$ & $24.78 \pm 5.81$ & $17.10 \pm 4.61$ & $<0.0001$ \\
\hline Total Protein (gm/dl) & $7.17 \pm 0.48$ & $7.30 \pm 0.40$ & $7.22 \pm 0.59$ & $7.15 \pm 0.72$ & Not significant \\
\hline Albumin (gm/dl) & $4.40 \pm 43$ & $4.31 \pm .42$ & $3.79 \pm 0.54$ & $3.37 \pm 0.46$ & $<0.0001$ \\
\hline Globulin (gm/dl) & $2.77 \pm 0.55$ & $2.99 \pm 0.55$ & $3.42 \pm 0.79$ & $3.78 \pm 0.81$ & $<0.0001$ \\
\hline Albumin/Globulin ratio & $1.68 \pm 0.54$ & $1.51 \pm 0.41$ & $1.18 \pm 0.35$ & $0.96 \pm 0.37$ & $<0.0001$ \\
\hline
\end{tabular}

Note: All data are expressed as mean \pm SD. p value $<0.05$ considered as statistically significant.

Total and direct bilirubin concentrations in serum were significantly lower in second and third trimester compared to nonpregnant and first trimester pregnant women. Serum ALT and AST activity was slightly but significantly increased in third trimester compared to nonpregnant, first and second trimester pregnant women. No significant increase in serum ALT and AST activity during first and second trimester compared to nonpregnant women. Nevertheless, all serum ALT and AST values remained below $31 \mathrm{U} / \mathrm{L}$, the upper normal limit in our laboratory. Serum ALP activity was significantly higher in third trimester compared with nonpregnant, first and second trimester pregnant women. Serum ALP activity was also significantly higher in second trimester compared to nonpregnant women. Serum GGT values were significantly lower in third trimester compared to nonpregnant, first and second trimester pregnant women.

There is no significant change in serum total proteins concentration. But serum albumin level was significantly lower and serum globulin concentration was significantly higher in all three trimester compared to nonpregnant women. Serum A/G ratio was significantly reduced in 
second and third trimester compared to nonpregnant and first trimester pregnant women.

\section{DISCUSSION}

Although the liver in some animals increases in size remarkably during pregnancy, there is no increase in size during human pregnancy. Histological evaluation of liver biopsies, including examination with electron microscope, has shown no distinct changes in liver morphology in normal pregnant women. But some of the laboratory tests used to evaluate hepatic function yield appreciably different results during normal pregnancy. Moreover, some of the changes are similar to those in nonpregnant patients with liver disease. ${ }^{1}$ In this prospective study, we measured liver function tests in healthy pregnant women which are in first, second and third trimester and in controls not receiving oral contraception.

Total and direct bilirubin concentration in our study was significantly lower in second and third trimester than control and first trimester pregnant women. A decrease in serum total bilirubin concentration has already been observed during pregnancy in various studies. ${ }^{5}$ Hemodilution could at least partly be responsible for the decrease in bilirubin concentration because albumin is the protein that transports bilirubin.

In our study we found significantly higher serum ALT and AST activity in third trimester compared to nonpregnant, first and second trimester pregnant women. No significant increase in ALT and AST activity during first and second trimester compared to nonpregnant women. All values were within normal limits. There no obvious explanation for this slightly increased serum ALT and AST activity during the second trimester. In two studies serum ALT and AST activity was higher in late pregnancy than in early pregnancy. ${ }^{6}$ Two another studies also shown serum AST values significantly higher in late pregnancy. ${ }^{6,7}$ An increase in AST and ALT levels was found during labour, which might be caused by contraction of uterine muscle. ${ }^{8}$ AST and ALT activity remain normal during pregnancy before labor and increased serum ALT of AST activities above reference range should lead to further investigations.

ALP originates mainly from two sources: liver and bone. The enzymes may be present in other tissue like intestine, kidney, placenta, leukocytes. The serum ALP values rises in third trimester. ${ }^{4}$ In our study also serum ALP activity was significantly higher in third trimester compared with nonpregnant, first and second trimester pregnant women. Serum ALP activity was also significantly higher in second trimester compared to nonpregnant women. Most studies shows increase in ALP activity in second and third trimester. ${ }^{5-7}$ Total alkaline phosphatase activity in serum almost doubles during normal pregnancy, but much of the increase is attributable to heat stable placental alkaline phosphatase isoenzymes. ${ }^{1}$ Because of this lack of specificity, the measurement of serum ALP activity is a poor test for the diagnosis of cholestasis during the third trimester of pregnancy.

Serum GGT activity in our study was significantly lowers during third trimesters than in controls, first trimester and second trimester pregnant women. Serum GGT activity considered to be normal in most published studies. 6,9 Decrease GGT activity in late pregnancy can be explained by inhibition of hepatic synthesis of GGT by hormone secretion during pregnancy. Even women suffering from viral hepatitis in early pregnancy have higher serum GGT activity than women with viral hepatitis in late pregnancy. The same phenomenon is also observed in women receiving oral contraceptives. ${ }^{10}$

In our study, no significant change in serum total proteins concentration, but serum albumin level was significantly lower and serum globulin concentration was significantly higher in all three trimester compared to nonpregnant women. Late in pregnancy albumin concentration reduced much compared to early pregnancy. Serum albumin/globulin ratio was significantly reduced in second and third trimester compared to nonpregnant and first trimester pregnant women. The reduction of albumin concentration, combined with a normal slight increase in serum globulin, results in decrease in albumin to globulin ratio similar to that seen in certain hepatic disease. ${ }^{1}$ It is necessary to bear in mind this phenomenon of hemodilution in the interpretation of all serum concentration values during pregnancy.

Yannick Bacq et al compared liver function tests in 103 pregnant women and 103 age matched control and found that serum albumin levels were significantly lower during all three trimesters. Serum ALP activity was significantly higher during the third trimester compared to nonpregnant women and during second trimester compared to first trimester. Serum ALT activity was slightly but significantly higher during second trimester of pregnancy compared with nonpregnant women. Serum AST activity was not significantly different in pregnant and nonpregnant women. Serum GGT activity was significantly lower during the second and third trimesters compared with nonpregnant women. Total and free bilirubin concentrations were significantly lower during all three trimesters, as was conjugated bilirubin during second and third trimesters. ${ }^{11}$

Loganathan G et al shows Serum albumin, AST and ALT were lower in pregnant mothers, whereas ALP and GGT were higher. $^{12}$

Salman MI shows no significant difference in serum AST between pregnant and nonpregnant women. Serum ALP was significant higher during the third trimester compared with second trimester and first trimester and with control group. During second trimester ALP was significantly higher than in first trimester and control group. Serum ALT activity was significantly higher 
during third trimester compared to first trimester and controls. Serum albumin levels were significantly lower during first, second and third trimester compared to controls. ${ }^{13}$

The main limitation of the present study is the low number of pregnant women included in the study. So newly designed prospective studies with large number of pregnant women are necessary to confirm our findings.

Thus identification and understanding of above changes in liver function tests in first, second and third trimester of normal pregnant women is important for the diagnosis of liver diseases during pregnancy, otherwise it can be misinterpreted as pathological and can also unmask or worsen preexisting disease.

\section{Funding: None}

Conflict of interest: None declared

Ethical approval: The study was approved by the Institutional Ethical Committee

\section{REFERENCES}

1. Cunningham FG. Maternal physiology. In: Kenneth JL, Steven LB, John CH, Larry CG, Katharine DW. Williams Obstetrics. $22^{\text {nd }}$ ed. New York, McGrawHill; 2005: 122-150.

2. Blackburn ST and Loper DL. Maternal, fetal and neonatal physiology. A clinical perspective, $3^{\text {rd }}$ ed. Elsevier saunders, Philadelphia. 2007: 92-104.

3. Rodin A, Duncan A, Quartero HWP, Pistofidis G, Mashiter G, Whitaker K, Crook D, et al. Serum concentrations of alkaline phosphatase isoenzymes and osteocalcin in normal pregnancy. $\mathbf{J}$ Clin Endocrinol Metab 1989;68:1123-1127.

4. Pradumna J, Amir A, Tarun G, Philip B. Liver function test and pregnancy. The Journal of Maternal, Fetal \& Neonatal Medicine 2009;22(3):274-83.
5. Knopp RH, Bergelin RO, Wahl PW, Walden CE, Chapman MB. Clinical chemistry alterations in pregnancy and oral contraceptive use. Obstet Gynecol 1985;66:682-690.

6. Salgo L, Pal A. Variation in some enzymes in amniotic fluid and maternal serum during pregnancy. Enzyme 1989;41:101-107.

7. Elliott JR, O'Kell RT. Normal clinical chemical values for pregnant women at term. Clin Chem 1971;17:156-157.

8. Meade BW, Rosalki SB. Serum enzyme activity in normal pregnancy and the newborn. Journal of Obstetrics and Gynaecology 1963;70:693-700.

9. Moniz C, Nicolaides KH, Keys D, Rodeck CH. Gamma-glutamyl transferase activity in fetal serum, maternal serum, and amniotic fluid during gestation. J Clin Pathol 1984;37:700-703.

10. Combes B, Shore GM, Cunningham FG, Walker FB, Shorey JW, Ware A. Serum gamma-glutamyl transpeptidase activity in viral hepatitis: suppression in pregnancy and by birth control pills. Gastroenterology 2007;72:271-274.

11. Back Y, Zarka O, Brechot JF, Mariotte N, Vol S, Tichet $\mathbf{J}$ and Weill $\mathbf{J}$. Liver function tests in normal pregnancy: A prospective study of 103 pregnant women and 103 matched controls. Hepatology 1996;23(5):1030-1034.

12. Loganathan G, George R, Eapen CE, Mathai M, Jasper P, Seshdri L, Shankar V, Paul S, Joseph G, Balsubramanian KA, Chandy GM. Liver function tests in normal pregnancy: a study from southern India. Indian Journal of Gastroenterology 2005;24:268-269.

13. Salman MI. Changes in liver function tests during pregnancy. Journal of al-anbar university for pure Science 2009;3(1):209-212.

DOI: $10.5455 / 2320-1770 . i j r \operatorname{cog} 20131225$

Cite this article as: Gohel MG, Joshi AG, Anand JS, Makadia JS, Kamariya CP. Evaluation of changes in liver function test in first, second and third trimester of normal pregnancy. Int J Reprod Contracept Obstet Gynecol 2013;2:616-20. 